\title{
Rapid surface hardening and enhanced tribological performance of 4140 steel by friction stir processing ${ }^{*}$
}

\author{
Cinta Lorenzo-Martin, and Oyelayo O. Ajayi \\ Argonne National Laboratory \\ Energy Systems Division \\ 9700 S. Cass Ave. \\ Argonne, IL, 60439 \\ Phone (630) 252-9021 \\ Fax (630) 252-4798 \\ ajayi@anl.gov
}

\begin{abstract}
:
Tribological performance of steel materials can be substantially enhanced by various thermal surface hardening processes. For relatively low-carbon steel alloys, case carburization is often used to improve surface performance and durability. If the carbon content of steel is high enough $(>0.4 \%)$, thermal treatments such as induction, flame, laser, etc. can produce adequate surface hardening without the need for surface compositional change. This paper presents an experimental study of the use of friction stir processing (FSP) as a means to hardened surface layer in AISI 4140 steel. The impacts of this surface hardening process on the friction and wear performance were evaluated under both dry and lubricated contact conditions in reciprocating sliding. FSP produced the same level of hardening and superior tribological performance when compared to conventional thermal treatment, using only $10 \%$ of the energy and without the need for quenching treatments. With FSP surface hardness of about $7.8 \mathrm{GPa}(62 \mathrm{Rc})$ was achieved while water quenching conventional heat treatment produced about $7.5 \mathrm{GPa}$ (61 Rc) hardness. Microstructural analysis showed that both FSP and conventional heat treatment produced martensite. Although the friction behavior for FSP treated surfaces and the conventional heat treatment were about the same, the wear in FSP processed surfaces was reduced by almost $2 \mathrm{x}$ that of conventional heat treated surfaces. The superior performance is attributed to the observed grain refinement accompanying the FSP treatment in addition to the formation of martensite. As it relates to tribological
\end{abstract}

\footnotetext{
* Work supported by the Department of Energy under Contract DE-AC02-06CH11357.
} 
performance, this study shows FSP to be an effective, highly energy efficient, and environmentally friendly (green) alternative to conventional heat treatment for steel.

\section{Introduction}

Hardening of the surface layer is a well-known approach to enhance the tribological performance of material. Mechanistically, both friction and wear phenomena at sliding contact interface involves some degree of plasticity, often at the asperity level. Since, hardness is a measure of a material's ability to resist plastic deformation under compressive stress of indentation, it is expected to have an effect of friction and wear phenomena. Consequently, surface hardening by a variety of techniques is commonly used to enhance tribological performance of machine elements and components. Some of the techniques in use today for surface hardening include thermal and thermo-mechanical treatments and different forms of coatings that can be applied by a variety of deposition methods.

In ferrous materials such as steel, which accounts for the vast majority of tribological components, the primary basic mechanism of surface hardening is by phase transformation to form the relatively hard martensitic phase in the surface layer. The process involves heating of the material, at least in the surface region, to a temperature in excess of the austenitizing temperature, then followed by rapid cooling thereby transforming the austenite phase into martensite. The method of application of heat is often the distinguishing feature of the numerous thermal hardening techniques. Heat can be applied in the conventional furnace, laser, electricity (induction), flame and many others. Each of the various methods has their own advantages and disadvantages. The method of choice is often guided by the specific component requirements and economics. 
Some variant of the thermal heat treatment process of steel material can also involve the change of the chemistry or composition of the near-surface material. These thermochemical processes include carburizing, nitriding, boriding, etc.

In general, most of the thermal heat treatment methods for steel are very energy and often capital intensive. In most case, the entire component must be treated, even though only a limited area involved in tribological contact may need hardening. Thermal distortion is also commonly observed in many heat treated parts, especially if a very high cooling rate is required for martensitic phase transformation. This can be a major problem especially in high precision components, in which case, post-heat treatment machining may be required in order to correct possible heat treatment related dimensional distortion.

Surface hardening of steel alloys can also be achieved through mechanical treatments. Grinding of steel material under appropriate conditions has been shown to lead to surface hardening comparable to the traditional heat treatment [1,2]. Similarly, machining operation of steel material under severe conditions has been shown to produce a hardened layer on the surface [3]. Other mechanical surface hardening methods that have been applied to steel materials include explosive impact, high energy shot peening, etc. [4]. All these techniques involve severe plastic deformation of surface layer that is undergoing hardening treatment. The heat generated by the process of severe plasticity can raise the temperature of the surface layer above the austenitizing temperature. Rapid cooling through heat dissipation into the bulk material can be fast enough for the formation of martensitic phase and consequent hardening of the surface layer. Thus, the basic mechanism of surface hardening of steel material by mechanical treatments also involve phase change, similar to traditional thermal treatment. 
Friction stir processing (FSP), is an off-shoot of friction stir welding which is a process used to joint metallic material in solid state via severe plastic deformation and mechanical mixing. In FSP, the process is not to join two pieces of materials, but to modify the microstructure of the surface layer of metallic material work piece [5,7]. FSP has been applied to many metallic materials and alloys to produce improvement in ductility, fatigue resistance and eliminate microstructural defects $[8,10]$. The FSP process involves plunging of a non-consumable rotating tool to the surface being processed until the tool shoulder contacts the work piece. This is then followed by lateral translation to cover area of interest. Significant heating is generated in the processed layer by the high strain rate severe plastic deformation of the processed area and the rubbing of the tool and workpiece material. Because of the ease of their plasticity, the bulk of investigations on application of FSP have been on low-melting point and soft alloys such as aluminum, magnesium and bronze. Increasingly more studies are being conducted on the application of FSP process to various grades of steel materials $[11,12]$. In terms of tribological application, FSP was recently applied to AISI 1080 steel [13] and AISI 420 steel [14] as a means to harden the surface and thereby enhance the friction and wear performance of the materials.

The vast majority of tribological components that are usually surface hardened are made of various grades alloy steel. One of such widely used alloy is the AISI 4140 steel. It is used for a variety of components in variety of industries ranging from aerospace to automotive. Furthermore, numerous surface hardening process are applied to the 4140 steel in order to enhance its tribological performance $[15,16]$. This paper presents an experimental study exploring the application of FSP as a method to harden the surface layer of 4140 steel alloy. The impacts of such hardening on the friction and wear 
behavior were assessed. Both the hardening and tribological performance attributes of FSP treatment are compared with traditional thermal hardening treatment of the same material.

\section{$\underline{\text { Experimental Details }}$}

Material:

AISI 4140 steel plate with a thickness of $6.5 \mathrm{~mm}$ in the annealed condition was used for this study. The typical nominal chemical composition of the material is 0.370.44 C, 0.10-0.35 Si, 0.65-1.10 Mn, 0.75-1.20 Cr, 0.15-0.35 Mo, $\leq 0.040 \mathrm{P}, \leq 0.040 \mathrm{~S}$, Bal- Fe. Flat test specimens prepared in the annealed condition are designed the baseline. Test samples were also fabricated from 4140 that is hardened by conventional heat treatment procedure. These samples were austenitized at $840^{\circ} \mathrm{C}$ and water quenched designated HT in the present study. Flat samples were also prepared from material from FSP treatment and designated FSP accordingly.

\section{Friction Stir Processing:}

There are many factors and variables involved in the optimization of friction stir processing or welding. These include FSP tool design and tool material, the tool rotating speed, travel speed and processing or plunging force. With friction stir processing or welding of steel, one of the most important inputs is the tool material. The two most common families of materials that have historically been used are poly-crystalline boron nitride (PCBN) based or refractory materials, such as tungsten-rhenium (W-Re) or lanthanated tungsten (W-La). While each of the material families have advantages and disadvantages, in the present study, the PCBN tools was used for FSP treatment due to 
their ability to have more intricate geometry, which aid in the mixing of the processed materials. There are also multiple grades of PCBN tools materials. For the present study, it was felt that toughness of the tool material was of overriding importance. Thus, Q60 grade was selected for its optimal toughness. The tool has a convex shoulder and stepped spiral pin geometry as shown in Fig. 1.

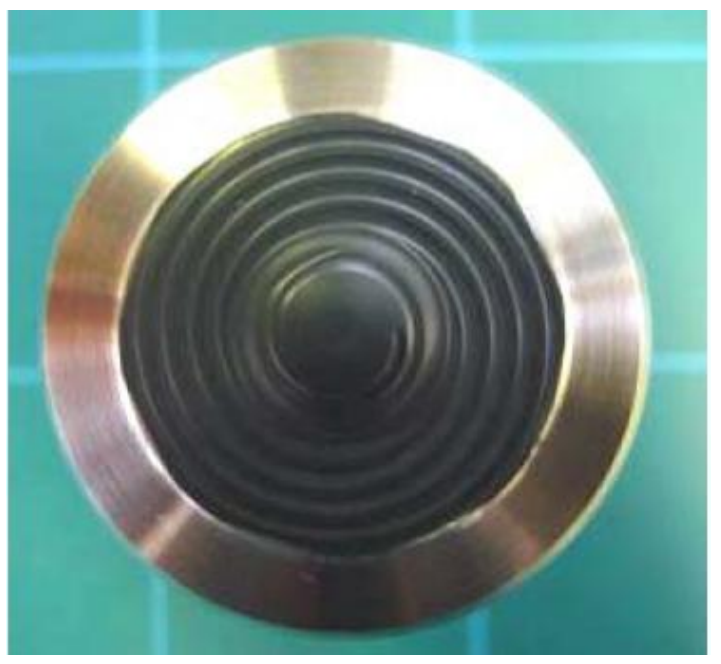

Figure 1: PCBN tool used for FSP

Friction stir processing to a depth of approximately $5 \mathrm{~mm}$ was done with the tool shown in Figure 1, using a $275 \mathrm{rpm}$ rotating speed, $2 \mathrm{~mm} / \mathrm{sec}$ translation speed and a force of about $45 \mathrm{kN}$. Inert Argon gas shielding was used during FSP to prevent oxidation. The tool temperature during FSP was measured to be approximately $940^{\circ} \mathrm{C}$.

\section{Microstructure and Hardness:}

The microstructures of FSP treated layer in comparison with that of conventional thermal treatment and the annealed baseline material were examined using the standard metallographic technique. Cross-section samples were prepared from FSP, heat treated and baseline material. Samples were mounted and polished, followed by etching with 
2\% Nital solution. Optical and scanning electron (SEM) microscopy were used to examine the microstructure.

Microhardness measurements were conducted on polished cross sectional samples of FSP treated, conventional heat treated and the baseline materials. The measurements were made with a Vickers indenter using Wilson Tukon microhardness tester at a load of $\operatorname{logg}(1 \mathrm{~N})$. Average surface hardness in each sample was estimated from five (5) repeat measurements at about $100 \mu \mathrm{m}$ from the surface. Several measurements were also made as a function of distance from the surface. For the FSP treated sample, a 2-D array of microhardness measurement were made to cover the FSP area, the heat affected area and the base material.

\section{Friction and Wear Testing}

Friction and wear tests were conducted with a ball-on-flat contact configuration in reciprocating sliding. Ball specimens are made of polished $12.7 \mathrm{~mm}(0.5$ ”) diameter hardened 52100 bearing steel with a surface roughness of $0.035 \mu \mathrm{m} \mathrm{Ra}$ and a hardness of about $8.0 \mathrm{GPa}\left(63 \mathrm{R}_{\mathrm{c}}\right)$. Rectangular flat specimens with $50 \times 30 \times 6.5 \mathrm{~mm}$ nominal dimensions were made from 4140 steel in three different conditions: the annealed baseline, heat treated (HT) water quenched, and FSP. The surfaces of all the flat specimens were ground to the same surface finish of $0.14 \mu \mathrm{m} \mathrm{Ra}$.

Oil lubricated friction and wear tests were conducted at three different loads of 25, 50 and $75 \mathrm{~N}$ which impose maximum Hertzian contact pressure of 1.17, 1.48, and $1.69 \mathrm{GPa}$, respectively, for a ball-on-flat contact. Reciprocating frequency of $1 \mathrm{~Hz}$ was used, with a stoke length of $10 \mathrm{~mm}$, translating to an average sliding velocity of $1 \mathrm{~cm} / \mathrm{s}$. Test duration was 1 hour and under ambient room temperature and air (35\% RH). All 
the tests were lubricated with basestock synthetic polyalphaolefin (PAO4) oil containing no additives and with a viscosity of $18 \mathrm{cSt}$ at $40^{\circ} \mathrm{C}$. Friction and wear tests were also conducted under dry contact condition using a normal contact load of $5 \mathrm{~N}$ (0.70 GPa) reciprocating frequency of $1 \mathrm{~Hz}$ for a duration of $30 \mathrm{~min}$ under ambient room condition.

The friction coefficient was continuously measured during each test. At the conclusion of the test wear was measured in the test specimen by optical profilometry technique. Worn surfaces were also characterized by both optical and SEM microscopy to assess wear mechanisms.

\section{$\underline{\text { Results }}$}

\section{$\underline{\text { Microstructure }}$}

Figure 2 shows the optical micrographs of the near surface microstructure of the baseline annealed, austenitized and water quenched and FSP treated 4140 steel material. The baseline material microstructure (Figure 2a) consists of pearlite and some primary ferrite phase as expected for a hypo-eutectoid steel such as 4140 with $0.4 \%$ carbon content. For the heat hardened specimen, the microstructure consisted primarily of martensite (Figure 2b). The cooling rate of water quenching is certainly sufficient to cause the austenite to martensite phase transformation. The microstructure of FSP treated surface is shown in Figure 2c. The processed material is fully dense and consists primarily of martensite. The microstructural evolution in the friction stir processed material results from the severe plastic deformation and the consequent heat generation, in addition to frictional heating of the FSP process. The temperature of the processed region exceeded the austenitizing temperature of the 4140 steel $\left(\approx 780^{\circ} \mathrm{C}\right)$ producing rapid 
austenitization. Indeed, the measured tool temperature in the present study was about $940^{\circ} \mathrm{C}$; certainly much higher than the austenitizing temperature of 4140 steel. The cooling rate after the tool passes is fast enough to "quench" the hot austenite phase, thereby forming the martensite phase. Grain refinement also occurred in the austenitic phase as a result of the severe plastic deformation making the formation of the martensite easier upon cooling. The microstructural evolution is similar to that reported for FSW of steel investigations [11-12].
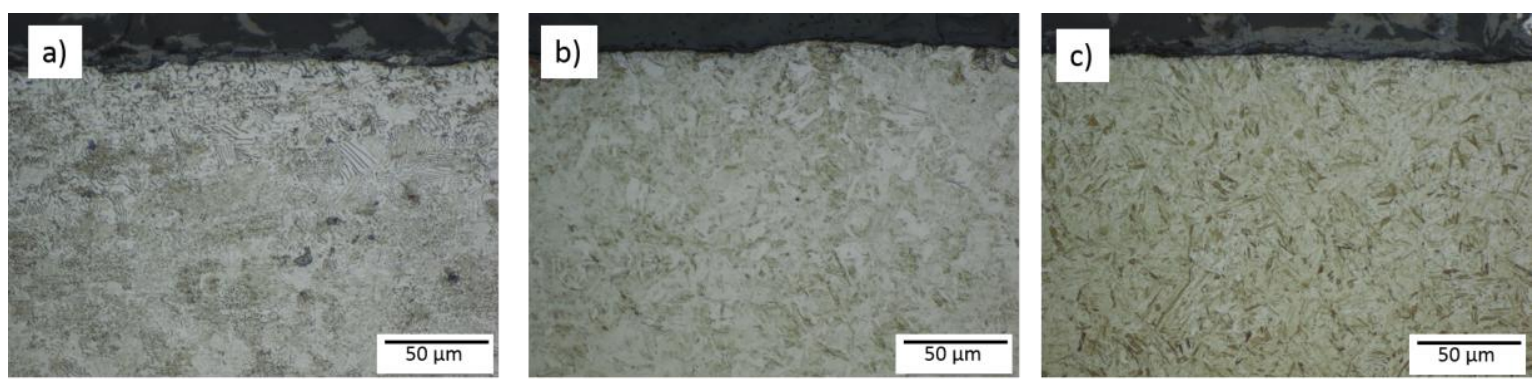

Figure 2: Optical micrograph of the 4140 steel microstructure of (a) baseline (b) conventional heat treatment and (c) FSP treated.

\section{$\underline{\text { Hardness }}$}

Figure 3 shows the hardness profile as a function of depth for the baseline annealed, heat hardened and FSP treated samples. For the FSP sample, the hardness measurements were conducted at the center of the processed region. The hardness of the baseline material was about 2.0 GPa and independent of depth as expected since it is in the annealed condition. Heat hardening by water quenching from austenitizing temperature increased the hardness to about 7.0 GPa; although the hardness near the surface was only about 6.2 GPa. In this sample, the hardness was also independent of depth. For steel with $0.4 \%$ 
carbon content, the maximum achievable hardness of martensite by heat treatment only is about 7.0 GPa [17]. Thus, the thermal hardened specimen used in the present study achieved the maximum martensite hardness for the material. FSP treatment produced hardening of the 4140 comparable to the thermal treatment as shown in the surface layer up to a depth of about 4-5 $\mathrm{mm}$ as shown in Figure 3. Beyond the depth of about $5 \mathrm{~mm}$, outside the FSP treated material, the hardness is the same as the baseline material. Thus, FSP can be viewed as a form of case hardening treatment for this steel materials. Some variations was observed in the measured hardness of the process region. The highest hardness of about 7.5 GPa was observed at the surface while values as low as 5.5 GP was observed at the middle of the case layer. This hardness variability in the FSP treated sample is best illustrated in Figure 4. The photo macrograph of the cross-section of the processed region is shown in Figure 4a, and the corresponding 2-D measured hardness map is shown in Figure 4b.

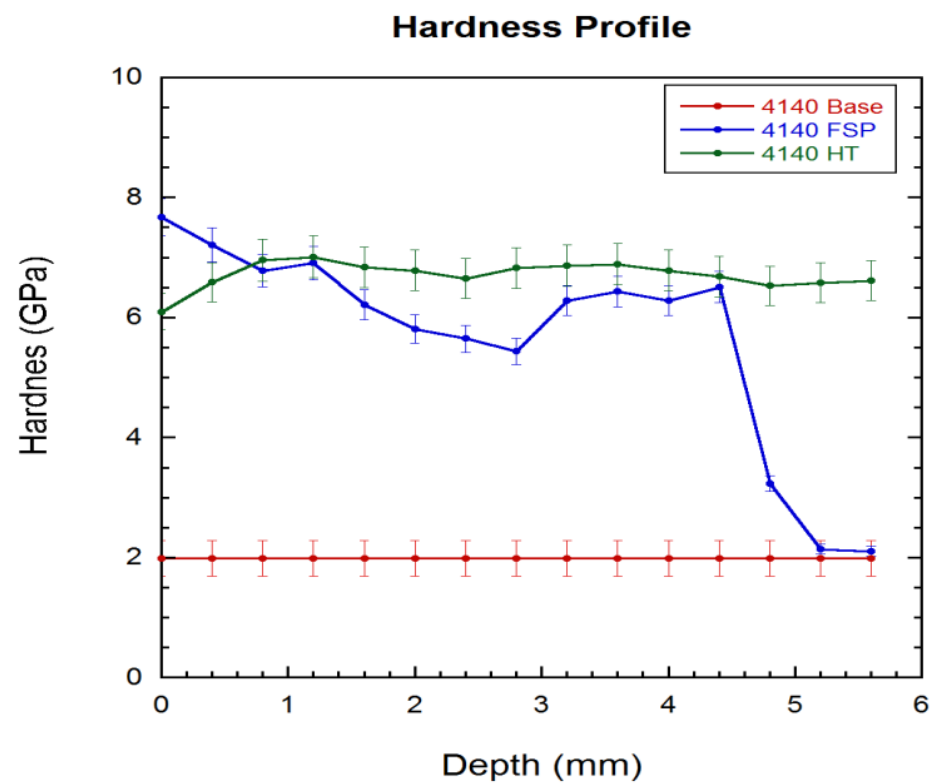

Figure 3: Hardness variation with depth for the baseline, heat hardened and FSP treated 4140 steel flats. 


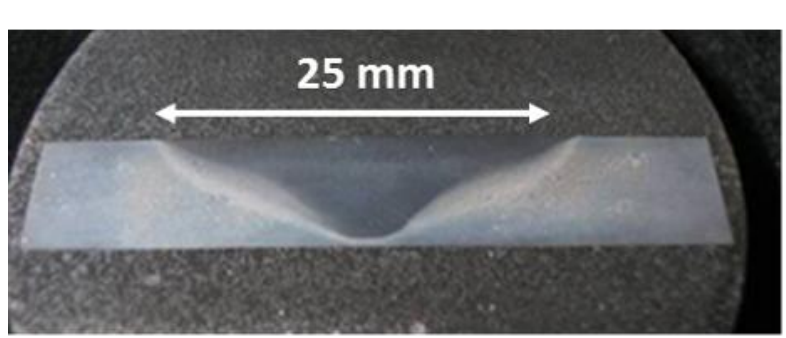

(a)

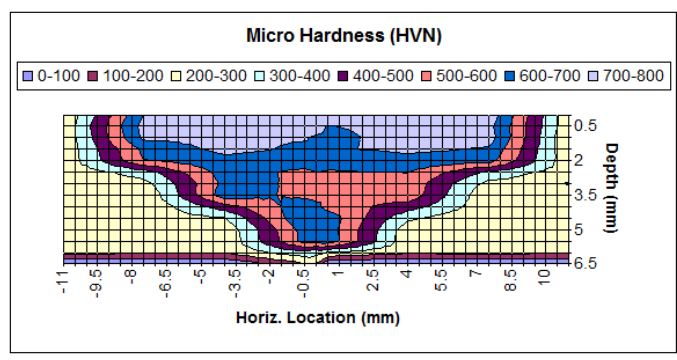

(b)

Figure 4: (a) Cross-section microstructure and (b) hardness map of FSP treated 4140 steel

\section{Friction and Wear}

Figure 5a shows the variation of friction coefficient with time during the dry sliding contact for the three conditions of the 4140 flat specimens. Both the baseline material and the heat hardened samples showed relatively low-friction coefficient at the beginning of the test. In both cases friction gradually increased for the duration of the test. The FSP treated sample on the other hand started sliding at a much higher friction coefficient. Although noisy, the friction was nearly constant for the duration of the test. By the end of the test, friction for the three were all trending toward each other, although the FSP specimen friction is still higher. The average friction coefficient for the entire duration of the test for the three materials is shown in Figure $5 \mathrm{~b}$ indicating the higher dry friction with FSP and about similar friction for baseline and heat treated specimens. 


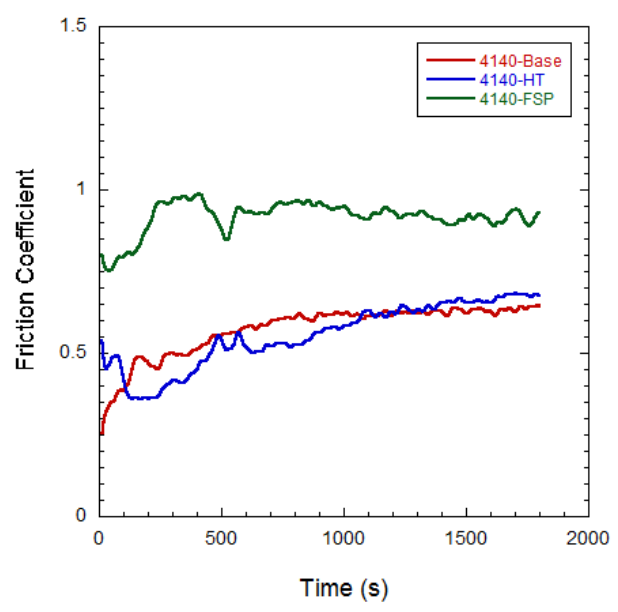

(a)

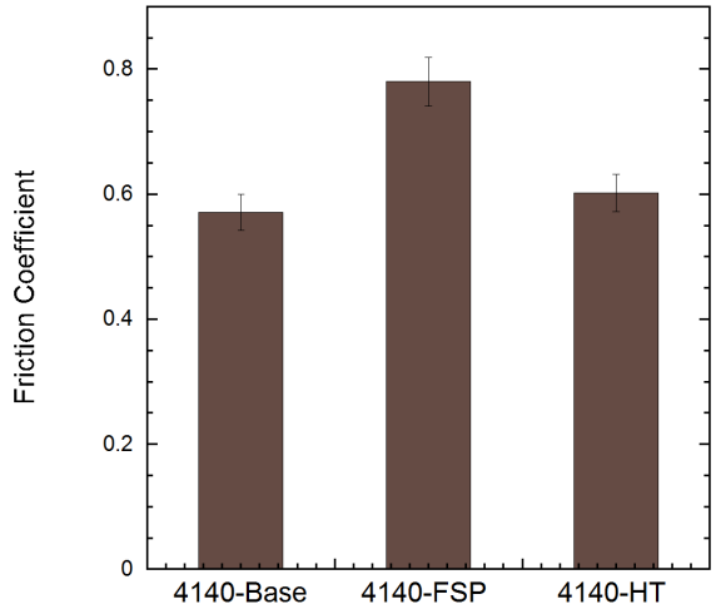

(b)

Figure 5: (a) Friction variation with time during dry sliding test (a) Average friction coefficient for the entire duration of test.

Although, the FSP treatment increased the friction during sliding contact, it showed much lower wear in both the flat and the ball counterface. Figure $6 \mathrm{a}$ and $6 \mathrm{~b}$ show the amount of wear in the 52100 steel ball counterface and the 4140 flat specimens respectively. The heat treated flat produced much more wear on the counterface ball compared to the baseline flat. This can be attributed to higher hardness of the heat treated material. The FSP treated flat however produced the least amount of wear on the counterface ball in spite of having the highest surface hardness of the three. This may be the result of microstructural refinement of the near surface layer by FSP. Both thermal heat treatment and the FSP treatment reduced wear in the flat specimens as shown in Figure 6b, again with FSP treated surface showing the lowest amount of wear. Optical micrographs of the wear track on the three flat specimen are shown in Figure 7. Both the 
baseline material and the heat treated specimen showed identical wear mechanism. There is evidence of abrasion, possible sliding fatigue wear and formation of transfer layer in patches $(7 \mathrm{a}$ and $7 \mathrm{~b})$. For the FSP treated flat, wear occurred primarily by abrasion and some limited amount of transfer layer patches (7c). Compared to the other two flats, the extent of surface damage and wear were much reduced.

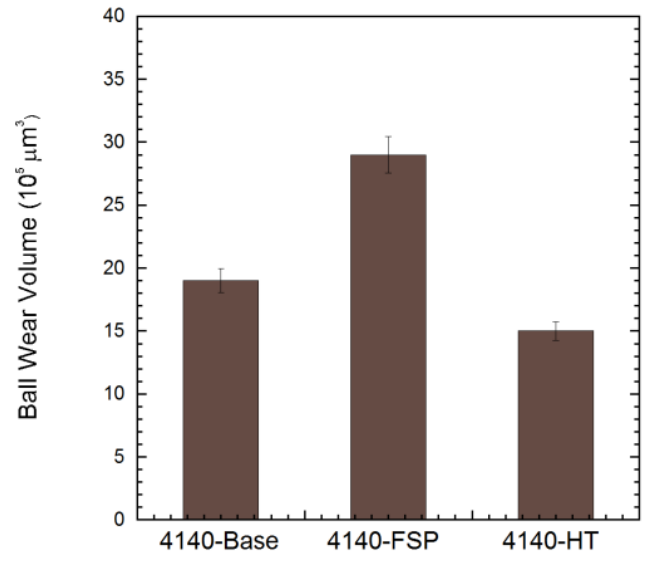

(a)

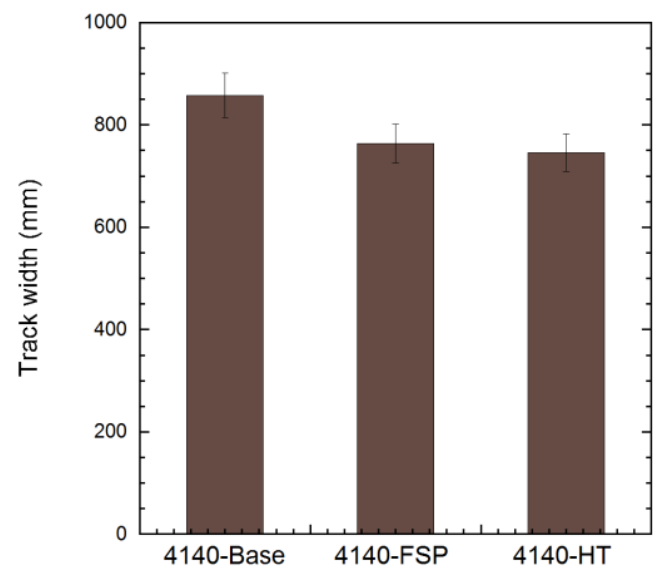

(b)

Figure 6: Measured wear in (a) ball specimen and (b) flat specimen during dry test.
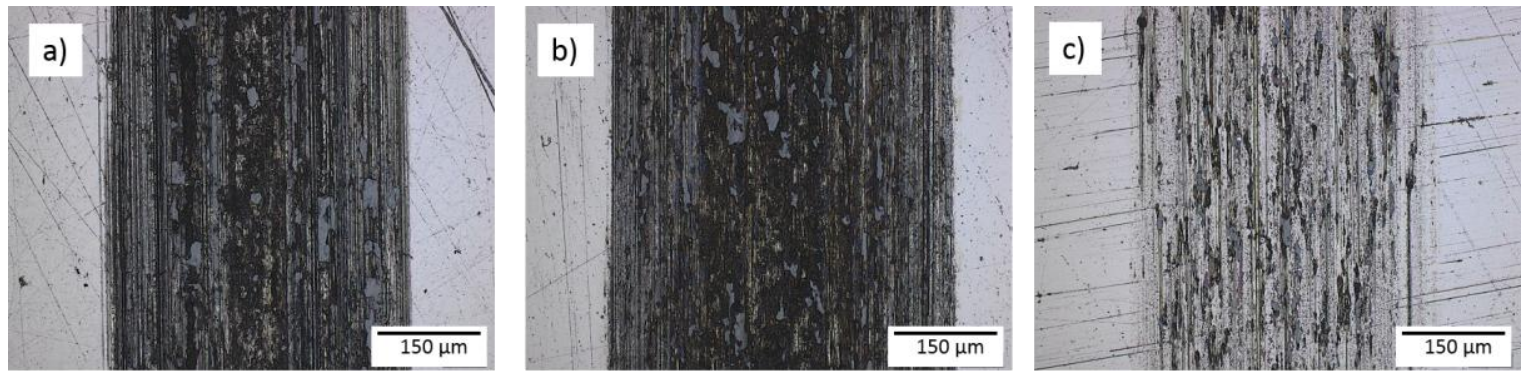

Figure 7: Optical micrograph of wear flat track in dry test (a) baseline (b) HT (c) FSP 
Under oil lubrication with PAO, the friction behavior is essentially the same for three material, i.e., baseline, heat treated and FSP treated. This is true for the three loads tested. Figures $8 \mathrm{a}$ and $8 \mathrm{~b}$ show the variation of friction coefficient with time for tests conducted at 25 and $75 \mathrm{~N}$, respectively. The measured friction coefficients are between 0.1 and 0.12 for all the contact pairs. The friction of the baseline material is slightly noisier compared to the hardened surfaces, especially at the low load of $25 \mathrm{~N}$. This may be indicative of more local plasticity at the asperity contacts of the softer annealed material compared to harder surfaces. The average friction coefficient for the entire duration of each of the lubricated tests is shown in Figure 8c. There was a slight reduction in average friction with load, but little difference between the three conditions of the flat specimen.

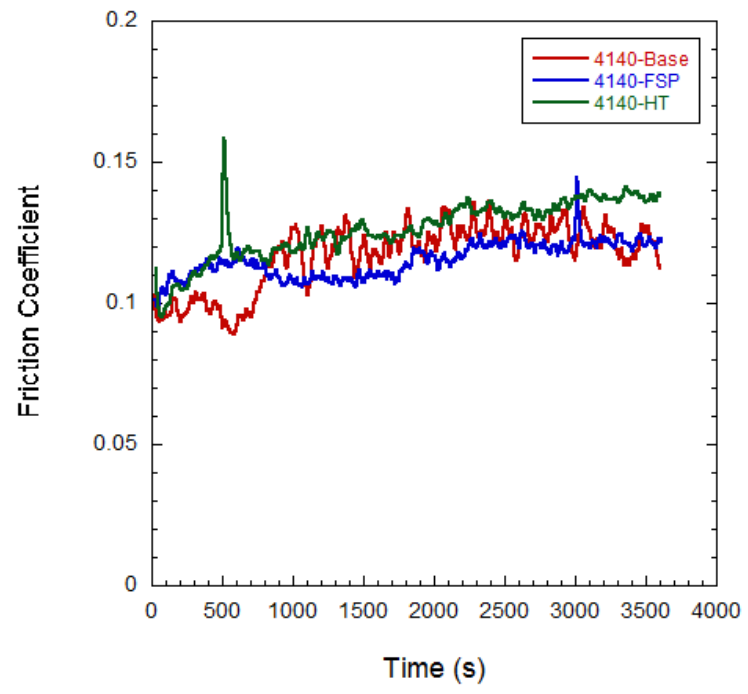

Figure 8a: Friction coefficient variation with time in lubricated contact at $25 \mathrm{~N}$ load 


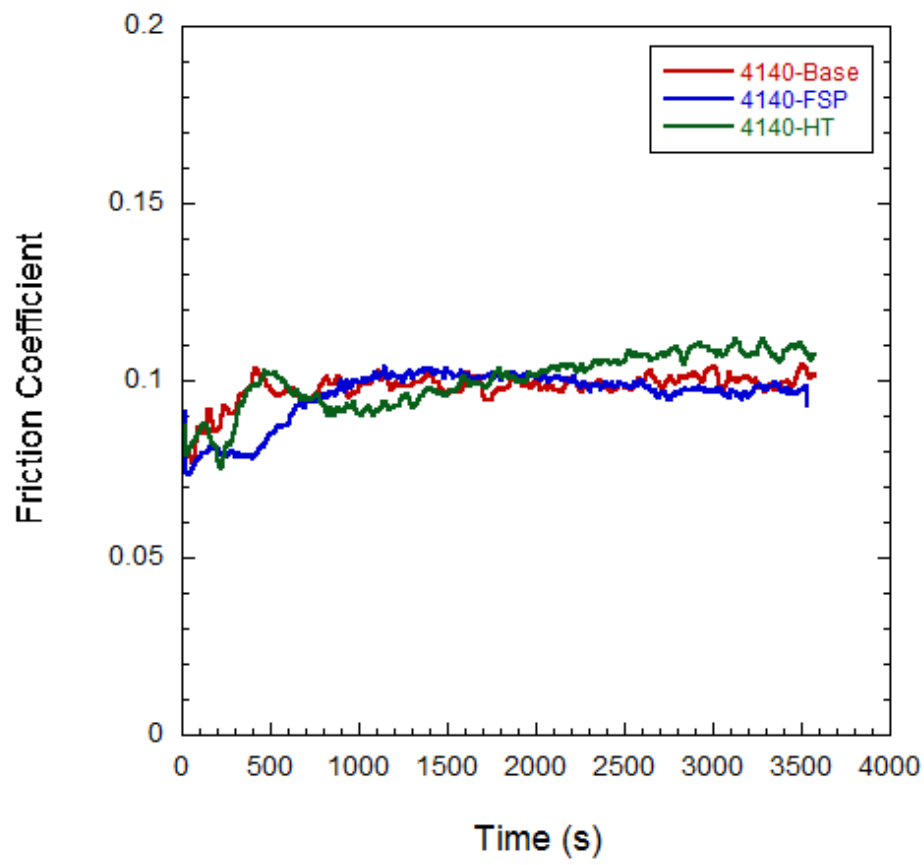

Figure 8b: Friction coefficient variation with time in lubricated contact at $75 \mathrm{~N}$ load.

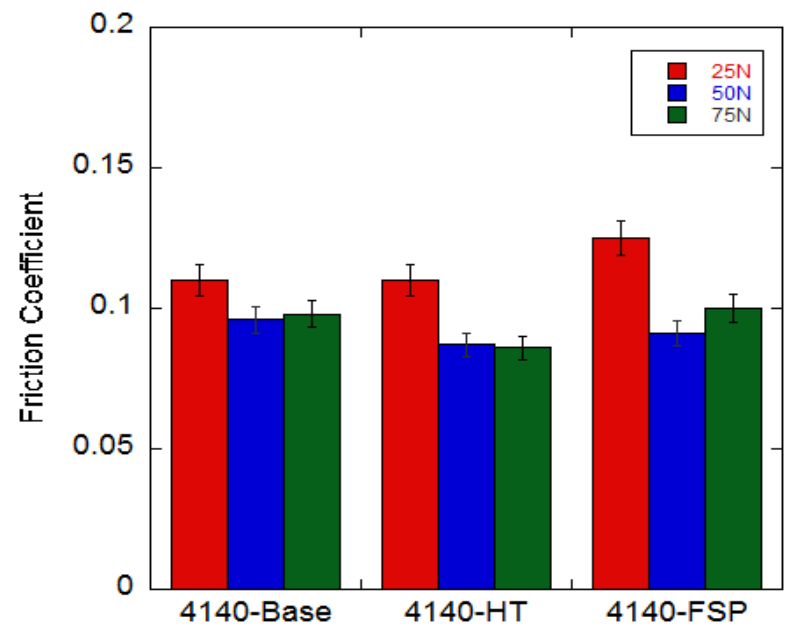

Figure 8c: Average friction coefficient for lubricated contact at different loads. 
In spite of minimal differences in the lubricated friction during test with the three different flats, the wear behaviors in both the counterface ball and the flat specimens were very different. Figure 9a shows the measured amount of wear at the conclusion of test for different flat at different loads. For the baseline material, the amount of on the 52100 ball increased with increasing load. For the hardened surfaces however, the least amount of wear on the ball was observed at load of $75 \mathrm{~N}$. This was observed to coincide with the formation of an oxide layer as shown in Figure 10 and verified with EDS analysis. Much more significant differences were observed in the flat specimen wear (Figure 9b). Significant reduction was observed in the wear of hardened surfaces compared to the baseline material. FSP treatment reduced the wear much more than thermal hardening. In all the flats, it is observed that the amount of wear increases with increasing load, but at much lower rate for FSP treatment. In general, the heat treatment reduced 4140 steel flat wear by about $5 \mathrm{X}$ compared to the baseline, while FSP reduced the wear by more than $30 \mathrm{X}$.

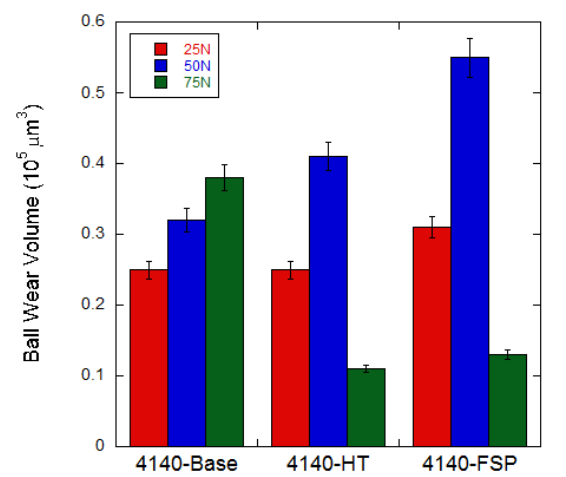

(a)

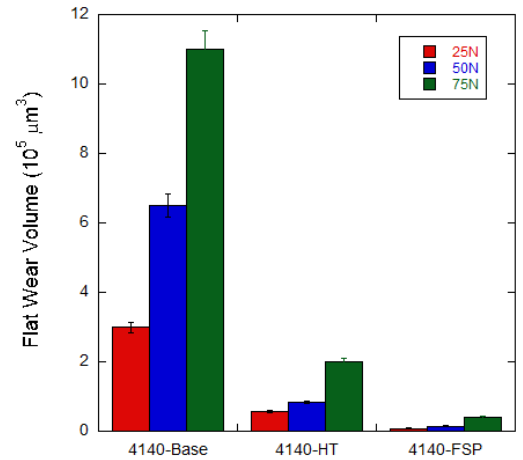

(b)

Figure: 9: Wear of (a) ball and (b) flat specimens in lubricated test. 

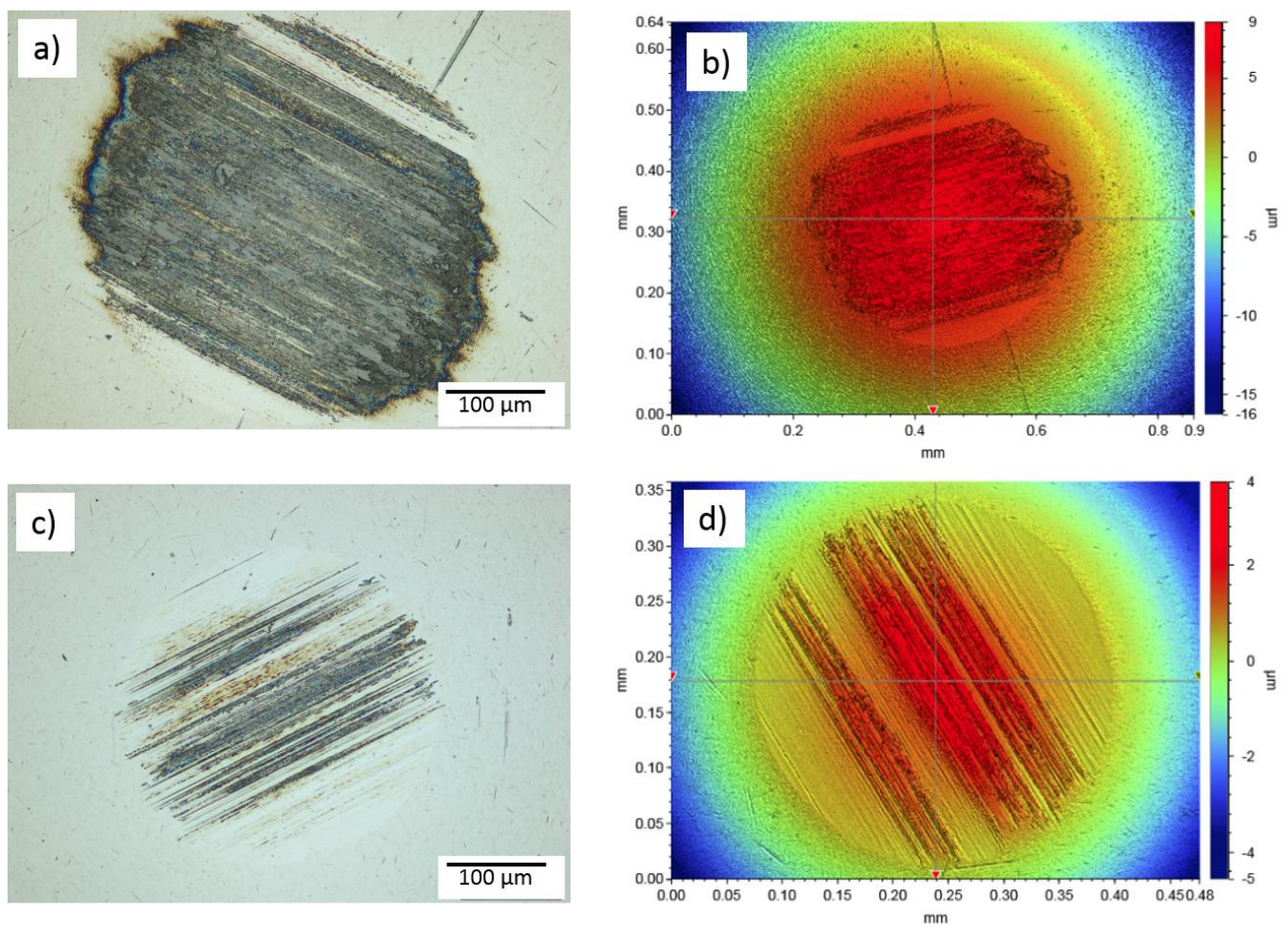

Figure 10: Optical micrograph and profilometry of ball wear scar rubbed against FSP flat at $75 \mathrm{~N}$ load (a and b) and 50N load (c and d) under lubricated condition.

Examination of the worn surface showed that wear in the baseline material involves significant amount of plastic deformation as indicated by material pile-up at the edge of track in Fig. 11b. SEM analysis indicates the wear mechanisms in the baseline material consist of abrasion, as shown by scratches in the direction of sliding, as displayed in Fig. 12a and fatigue as illustrated by cracks formation and material loss, as seen in Fig. 12b. In heat hardened flats, less plastic deformation occurred. There is no evidence of material pile-up at the edge and material removal occurred primarily by abrasion, as shown Fig. 12a. The increase in hardness is expected to reduce the amount of plastic deformation, which also reduces the extent of fatigue damage. Nonetheless, considerable amount of material removal did occur. In the FSP flat, minimal surface 
damage and material removal occurred. There were only a few scratches and minimal plastic deformation, as shown in Fig. 13. Indeed SEM analysis show occurrence of only superficial damage and material removal. An original grinding mark running across the wear track can still be clearly seen in Fig. 14; illustrating minimal material removal.
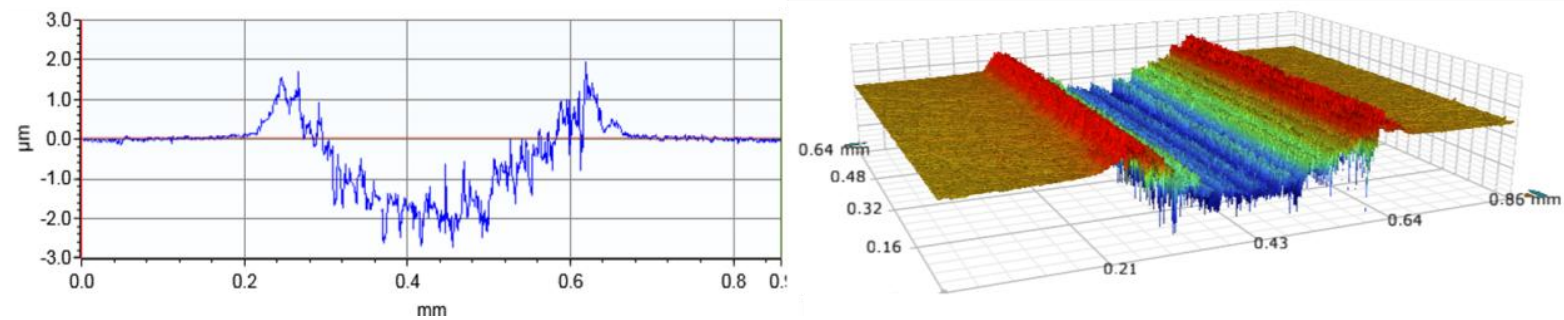

Figure 11: Optical profilometry of wear tack in the baseline unhardened flat show material pile up at edge of track.
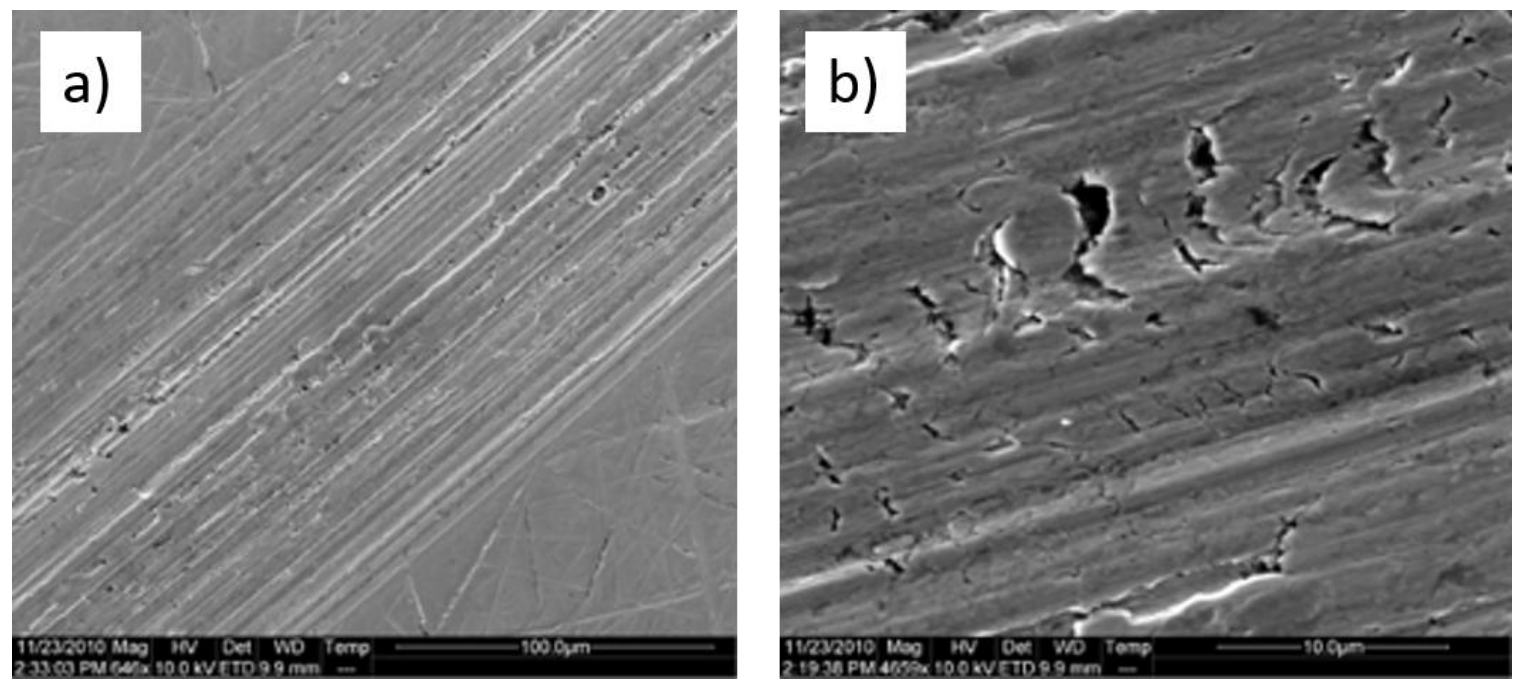

Figure 12: SEM micrograph of wear track in HT flat showing wear by abrasion and fatigue mechanisms.
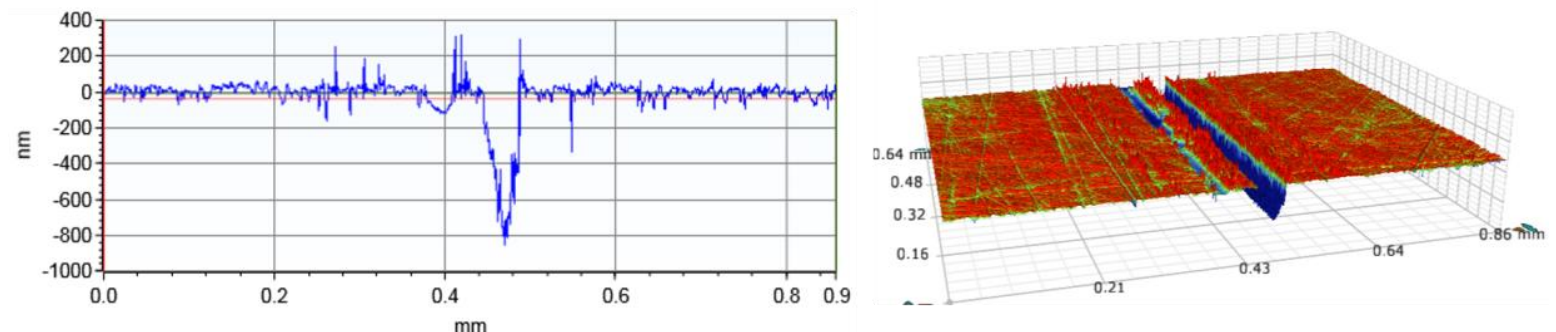

Figure 13: Optical profilometry of wear track on FSP flat. 


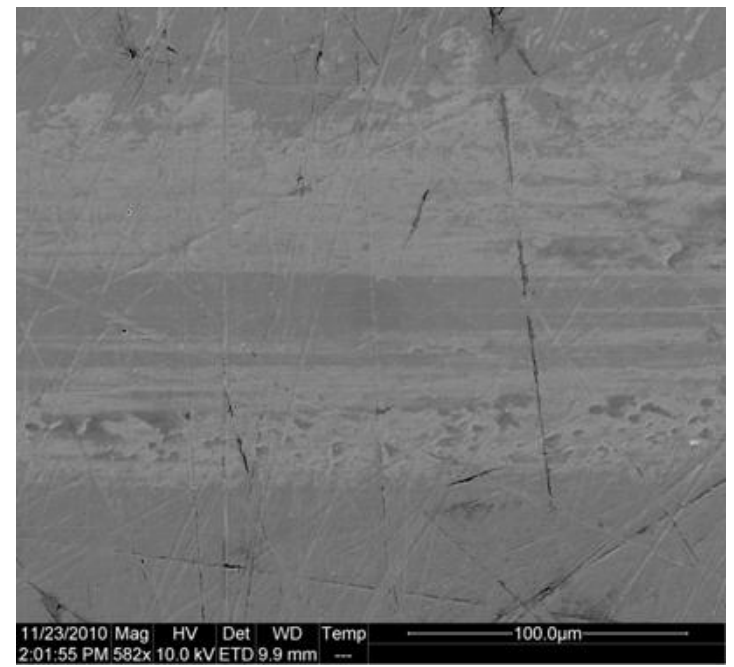

Figure 14: SEM micrograph of wear track on FSP flat show minimal wear or damage

\section{Discussion:}

Results of the present study show that FSP is an effective, rapid and energy efficient means of hardening steel surfaces, especially if the carbon content is about $0.4 \%$ and higher. Such steel composition can be thermally hardened without the need to change the near surface carbon content as usually done in carburizing heat treatment. Indeed, FSP was observed to enable hardening of 4140 steel surface layer to a level higher than the maximum hardness expected for the alloy, based on its carbon content. For steel with $0.4 \%$ carbon content, the maximum hardness achievable by heat treatment of austenitizing and quenching is about 7.0 GPa. That was in fact, that hardness achieved by the thermal treatment in the present study. With FSP, surface hardness of about 7.8 GPa was obtained. 
This remarkable surface hardening by FSP is attributed to three mechanisms; namely phase transformation, grain refinement and increased $\mathrm{C}$ solubility. From the measured tool temperature of $940^{\circ} \mathrm{C}$ observed in the present study and reported temperatures well in excess of $1000^{\circ} \mathrm{C}$ during friction stir welding of steel materials, the FSP material will experience rapid heating to temperatures, well in excess of the austenitizing temperature for 4140 steel $\left(780^{\circ} \mathrm{C}\right)$. Once the tool passes, rapid cooling occurs resulting in the transformation of the austenite to much harder martensite phase. Microstructural analysis of FSP in the present study verified occurrence of this phase transformation. The severe plasticity involved in the FSP process also leads to substantial grain refinement. Such grain refinement of the austenite phase will produce ultra-fine grained martensite upon phase transformation. According to the Hall-Patch relationship, such ultra-fine grained martensite will exhibit enhanced strength (hardness) and ductility.

Another common way of increasing steel hardness besides grain refinement is to increase the carbon content in the austenite phase before transformation to martensite. During convention heat treatment, parts are often soaked at the austenitizing temperature to allow dissolution of carbide particle and cementite in the pearlite. This often results in grain growth, unless extraordinary measures are taken as in rapid heat treatment [18]. It is also well known the severe plastic deformation increases the dissolution of cementite in steel $[19,20]$. Since FSP involves severe plastic deformation, enhanced dissolution of the cementite is expected, thereby increasing the carbon content in the austenite even though the process time is short. The increased carbon content will increase the hardenability of the processed material and consequently higher hardness upon 
quenching. Thus, the grain refinement and the enhanced carbon dissolution accounts for higher hardness of FSP treated steel compared to traditional heat treatment.

Although, the present study demonstrates that FSP is a potential method to rapidly harden steel surfaces by creating a case layer of hard processed material, some major technical barriers exist. One of the main technical challenges for the process is the tool material, especially for steels with high hardenability. The most common tool material used for FSP include different grades of tool steel, some tungsten alloys, such as Densimet, and tungsten carbide (WC). These tool materials are adequately durable for relatively soft materials. However for hard materials such as alloy steel with good hardenability, the current crop of tool materials are not durable enough. Consequently, the tool materials that have been used for FSP of steel thus far include PCBN, high refractory alloys, such as W-Re alloys; all of which are very expensive. Because of the high temperatures the tools will experience during FSP of steel material, the durability of even these expensive tool material is not assumed. There is therefore a need for new generation tool material for large industrial scale FSP processing of tribological steel materials.

The surface hardening produced by FSP in the present study translated to significant improvement in tribological performance under both dry and boundary lubricated condition. The effect of FSP treatment on friction is minimal, especially under lubricated conditions in comparison with heat hardened and annealed material. However, it produced substantial reduction in wear of the 4140 steel material. More than $30 \mathrm{X}$ reduction in wear was observed with FSP treatment when compared to conventional thermal treatment. The remarkable improvement is associated with the microstructural 
modification of the near surface material by FSP as compared to thermal treatment. Wear mechanisms was observed to be primarily by abrasion and fatigue. The enhanced hardness of FSP is expected to reduce the extent of abrasion and the grain refinement resulting from the process is expected to reduce level of damage and wear by fatigue when compared to surface hardening by thermal treatment.

\section{Conclusion:}

This paper presents a study of the impact of FSP on surface hardening and the associated impact on the friction and wear behavior of Alloy 4140 steel material. The results showed that the steel can be successfully hardened to a level superior to the conventional heat treatment and quenching procedure. While the friction behavior of the baseline, heat hardened and FSP materials are similar, significant improvement in the wear performance was observed with FSP. Hardening processes, both conventional FSP, reduced wear but the wear with FSP is less than half of the conventional method. It also appears that wear in FSP material is less dependent on the contact load, when compared to the baseline and other heat treatment. FSP also changed the wear mechanisms in the 4140 steel material. All these improvements in wear behavior is attributed to the effect of FSP on the microstructure of near-surface layer of the material. The extreme grain refinement resulting from FSP resulted in the formation of ultrafine martensite phase in the processed material.

\section{Acknowledgements:}


This work was supported by U.S. Department of Energy, Energy Efficiency and Renewable Energy, Office of Vehicle Technologies, under contract DE-AC0206CH11357. The electron microscopy was accomplished at the EMC at Argonne National Laboratory, a U.S. Department of Energy Office of Science Laboratory operated under Contract No. DE-AC02-06CH11357 by UChicago Argonne, LLC.

\section{References:}

1. T. Brockhoff, “Grind-Hardening: A Comprehensive View," Annals of CIRP, 48, (1999) 255-260.

2. E. Brinksmeier and T. Brookhoff, "Utilization of Grinding Heat as a New Heat Treatment Process," Annals of CIRP, 45 (1996), 283-286.

3. B J. Griffiths and D. C. Furze, “Tribological Advantage of White Layers Produced by Machining,” ASME J. Tribology, 109 (1987), 338-342.

4. Z. Tong, Z. M. Shi, S. J. Tong, D. W. Wang and P. F. Li, "Surface Nanocrystallization, Austenization and Hardening of Medium Carbon Steel by an Explosive Impact Technique,” Surf. Coat. Tech; 251, (2014) 293-299.

5. Z. Y. Ma, "Friction Stir Processing Technology: A Review Metall. Mat. Trans. A (2008), 642-658.

6. R. S. Mishra and Z. Y. Ma, "Friction Stir Welding and Processing," Mater. Sci. Engr. R50 (2005), 1-78. 
7. S. Lathabai, R. Migeon, V. K. Tyagi, R. G. O’Donnel and Y. Estrin, “Friction Stir Processing: A Technique for Microstructural Refinement in Metallic Materials," Mater. Sci. Forum, Vol. 618-619 (2009) 63-67.

8. M. W. Mahoney, C. Fuller, W. H. Bingel and M. Celabrese, "Friction Stir Processing of Cast NiAl Bronze,” Mater. Sci. Forum Vol. 539-543 (2007), 3721-3726.

9. P. S. De, R. S Mishra, C. B. Smith, "Effect of Microstructure on Fatigue Life and Fracture Morphology in an Aluminum Alloy," Scripta Materialia, 60 (7), 2009, pp. 500503.

10. R. S. Mishra, M. W. Mahoney, S. X. McFadden, N. A. Mara and A. K. Mukherjee, "High Strain Rate Superplasticity in a Friction Stir Processed 7075 Al Alloy," Scripta Mater. 42 (2000) 163-168.

11. Y. S. Sato, H. Yamanoi, H. Kokawa, and T. Furuhara, "Microstructural Evolution of Ultrahigh Carbon Steel during Friction Stir Welding,” Scripta Mat. 57 (2007), 557560.

12. M. Ghosh, K. Kumar and R. S. Mishra, “Analysis of Microstructural Evolution during Friction Stir Welding of Ultrahigh-Strength Steel," Script. Mater. 63 (2010) 851 854.

13. S. H. Aldajah, O. O. Ajayi, G. R. Fenske and S. David, "Effect of Friction Stir Processing on Tribological Performance of High Carbon Steel,” Wear, 267 (2009), $350-355$.

14. S. Dodds, A. H. Jones, and S. Cater, "Tribological Enhancement of AISI 420 Martensitic Stainless Steel through Friction-Stir Processing,” Wear, 302, (2013), 863877. 
15. M. Ulutan, O. N. Celik, H. Gasan and U. Er, "Effect of Different Surface Treatment Methods on the Friction and Wear Behavior of AISI 4140 Steel,” J. Mater. Sci. Technol. 26 (2010) 251-257.

16. Y. Totik, R. Sadeler, H. Altun and M. Gavgali, "The Effects of Induction Hardening on Wear Properties of AISI 4140 Steel in Dry Sliding Conditions," Materials and Design, 24 (2003) 25-30.

17. W. C. Leslie, “Physical Metallurgy of Steel,” Hemisphere Publishing Corp., 1981.

18. R. A. Grange, “The Rapid Heat Treatment of Steel,” Met. Trans. 2 (1971), 65-78.

19. A. V. Korznikov, Y. V. Ivanisenko, D. V. Laptionok, I. M. Safarov, V. P. Pilyugin, and R. Z. Valiev, "Influence of Severe Plastic Deformation on Structure and Phase Composition of Carbon Steel,” Nanostructure Materials, 4 (1994) 159-167.

20. B. B. Straumal, S. V. Dobatkin, A. O. Rodin, S. G. Protasova, A. A. Mazilkin, D. Goll and B. Baretzky, "Structure and Properties of Nanograined Fe-C Alloys after Severe Plastic Deformation,” Adv. Engr. Mater. 13 (2011), 463-469. 